Pacific Journal of Mathematics

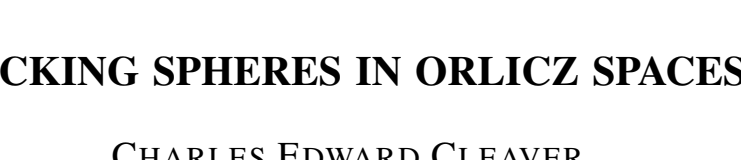




\title{
PACKING SPHERES IN ORLICZ SPACES
}

\author{
Charles E. Cleaver
}

\begin{abstract}
A collection of open balls of radius $r$ can be packed in the unit ball $U$ of a Banach space provided each ball is a subset of $U$ and the intersection of any two is empty. In an infinite dimensional Banach space, it is possible to find a largest number $\Lambda$ so that if $r \leqq \Lambda$ then an infinite number of spheres of radius $r$ can be packed in $U$. In this paper, upper and lower bounds are found for this number in Orlicz spaces.
\end{abstract}

For the space $l_{2}$, this number was found by Rankin [7] to be $1 /(1+\sqrt{2})$ and this result was extended in [1] to show that the number in $l_{p}(1 \leqq p<\infty)$ is $1 /\left(1+2^{1-1 / p}\right)$. In 1970 Kottman [4] showed that $1 / 3 \leqq \Lambda \leqq 1 / 2$ for any Banach space. More recently, Wells and Williams [10] used a generalized Riesz-Thorin interpolation theorem to obtain the exact value of $\Lambda$ in the $L^{p}(\mu)(1 \leqq p<\infty)$ spaces with some restrictions on the measure space when $2<p<\infty$. The results in this paper include all the above and also show that all restrictions can be removed in the $L^{p}$ case. Recent results have demonstrated that the structure of Orlicz spaces is quite different from $L^{p}$ spaces and very little seems to be known in the Orlicz case. The packing criteria lead to some results on isometric embeddings of subspaces and to notions of noncompactness.

2. Preliminaries. An Orlicz function $M$ will be a continuous convex nondecreasing function defined for $x \geqq 0$ and such that $M(0)=0, M(\infty)=\infty$ and $M(x)>0$ for $x>0$. The Orlicz space $L_{M}(X, \mathscr{A}, \mu)\left(=L_{M}\right)$ is the set of measurable scalar-valued functions defined on the measure space $(X, \mathscr{A}, \mu)$ such that $f \varepsilon L_{M}$ if and only if $\|f\|^{\prime}<\infty$ where

$$
\|f\|_{M}^{\prime}=\inf \left\{k>0: \int_{X} M\left(\frac{|f|}{k}\right) d \mu \leqq 1\right\} .
$$

For each Orlicz function $M$, a complementary function $N$ is defined by

$$
N(x)=\sup \{x y-M(y): 0<y<\infty\}
$$

If $M(x)=\int_{0}^{x} p(t) d t$ where $p$ is a right continuous nondecreasing function, then $N(p(x))=x p(x)-M(x)$ (cf [5]). Using this function, another norm can be defined on $L_{M}$ 


$$
\|f\|_{M}=\sup \left\{\int_{X}|f g| d \mu:\|g\|_{N}^{\prime} \leqq 1\right\} .
$$

These norms are equivalent if every set of positive $\mu$-measure contains a subset of positive finite $"$-measure and in this paper the latter will be used. In the case of $M(x)=x^{p}, p>1$, it follows that $\|f\|_{p}=\|f\|_{M}^{\prime}=K\|f\|_{M}$ where $K$ is independent of $f$ (cf [11]). It will be assumed in the remainder of the paper that $M$ is chosen so that the simple functions are dense in $L_{M L}$.

If $M_{1}$ and $M_{2}$ are two Orlicz functions then $M_{s}$ will denote the inverse of $M_{s}^{-1}=\left(M_{1}^{-1}\right)^{1-s}\left(M_{2}^{-1}\right)^{s}$ for $0 \leqq s \leqq 1$, where $M^{-1}$ is the unique inverse of the Orlicz function $M$. The function $M_{s}$ is an Orlicz function and satisfies most of properties of $M_{1}$ and $M_{2}$ including the fact that the simple functions are dense in $L_{M_{s}}$ if the same is true in $L_{M_{1}}$ and $L_{M_{2}}$. The complementary function to $M_{s}$ is not always the same as the inverse of $N_{s}^{-1}=\left(N_{1}^{-1}\right)^{1-s}\left(N_{2}^{-1}\right)^{s}$ where $N_{1}$ and $N_{2}$ are the respective complements of $M_{1}$ and $M_{2}$. However, the complement of $M_{s}$ and the inverse of $N_{s}^{-1}$ qenerate the same Orlicz space with equivalent norms (cf [8]). Since the complementary function is the one of interest in this paper, $N_{s}$ will denote the complement of $M_{s}$.

One condition which guarantees the separability of $L_{M}$ is the $\Delta_{2}$-condition. An Orlicz function is said to satisfy the $A_{2}$-condition at $\infty$ if $\lim _{x \rightarrow \infty} \sup M(2 x) / M(x)<\infty$. In the case of sequence spaces, separability occurs if and only if the $\Delta_{2}$-condition holds at 0 . A necessary and sufficient condition that $M$ satisfy the $\Delta_{2}$-condition is that $\lim _{x \rightarrow \infty} \sup x M^{\prime}(x) / M(x)=\alpha<\infty$ where $M^{\prime}(x)$ is the derivative of $M$ (cf [5], p. 24). If $M^{\prime}$ and $N^{\prime}$ are both continuous where $N$ is the complement of $M$, then this condition is equivalent to

$$
\liminf _{x \rightarrow \infty} \frac{x N^{\prime}(x)}{N(x)}>\alpha / \alpha-1
$$

This and elementary calculus lead to a lemma that will be useful in later sections.

Lemma 2.1. Let $M$ and $N$ be complementary functions with $M^{\prime}$ and $N^{\prime}$ continuous. If

$$
\alpha=\limsup _{x \rightarrow \infty} \frac{x M^{\prime}(x)}{M(x)}
$$

then

$$
\liminf _{x \rightarrow \infty} \frac{N^{-1}(x)}{N^{-1}(2 x)} \geqq \frac{1}{2^{(\alpha-1) / \alpha}}
$$


3. Interpolation. In this section a generalized interpolation theorem is described and then applied to obtain inequalities that will be useful in next section. This theorem generalizes Theorem 1 in [8] and follows the development in [10] of the $L_{p}$ case.

Let $\left(X_{1}, \mu_{1}\right),\left(X_{2}, \mu_{2}\right), \cdots,\left(X_{n}, \mu_{n}\right)$ be measure spaces and $M=$ $\left(M_{1}, M_{2}, \cdots, M_{n}\right)$ be an $n$-tuple of Orlicz functions. Define the direct $\operatorname{sum} \oplus L_{M_{k}}\left(\mu_{k}\right)$ by

$\bigoplus L_{M_{k}}\left(\mu_{k}\right)=\left\{f=\left(f_{1}, f_{2}, \cdots, f_{n}\right) \mid f_{k} \varepsilon L_{M_{k}}\left(\mu_{k}\right), k=1,2, \cdots, n\right\}$ with usual addition and scalar multiplication. For each $r, 1 \leqq r \leqq \infty$ and each $n$-tuple $\lambda=\left(\lambda_{1}, \cdots, \lambda_{n}\right)$ of positive weights, introduce the following norm on $\oplus L_{M_{k}}\left(\mu_{k}\right)$,

$$
\|f\|_{M, r}= \begin{cases}\left\{\sum_{k=1}^{n}\left\|f_{k}\right\|_{M_{k}}^{r} \lambda_{k}\right\}^{1 / r} & 1 \leqq r<\infty \\ \max _{1 \leqq k \leqq n}\left\|f_{k}\right\|_{M_{k}} & r=\infty .\end{cases}
$$

The space of all $f$ such that $\|f\|_{M, r}<\infty$ is a Banach space and will be denoted by $L_{M}^{r}(\lambda)$.

For two $n$-tuples $M_{1}=\left(M_{11}, M_{12}, \cdots, M_{1 n}\right)$ and $M_{2}=\left(M_{21}, M_{22}, \cdots, M_{2 n}\right)$ define $M_{s}=\left(M_{s 1}, M_{s 2} \cdots, M_{s n}\right), 0 \leqq s \leqq 1$, where $M_{s k}$ is the inverse of the function $M_{s k}^{-1}=\left(M_{1 k}^{-1}\right)^{1-s}\left(M_{2 k}^{-1}\right)^{s}, k=1,2, \cdots, n$.

Now let $\left(Y_{1}, \nu_{1}\right),\left(Y_{2}, \nu_{2}\right), \cdots,\left(Y_{m}, \nu_{m}\right)$ be another collection of measure spaces, $\eta=\left(\eta_{1}, \cdots, \eta_{m}\right)$ and define $m$-tuples $Q_{1}, Q_{2}$ in the same manner as $M_{1}$ and $M_{2}$. Letting $X=\left(X_{1}, X_{2}, \cdots, X_{n}\right)$ and $Y=\left(Y_{1}, Y_{2}, \cdots, Y_{m}\right)$, the following interpolation theorem was proved in $[2]$.

THEOREM 3.1. Let $1 \leqq r_{i}, t_{i} \leqq \infty, i=1,2,0 \leqq s \leqq 1$ with $1 / r=$ $1-s / r_{1}+s / r_{2}, 1 / t=1-s / t_{1}+s / t_{2}$ and suppose $M_{i}$ and $Q_{i}, i=1,2$, are defined on $X$ and $Y$ respectively. If $T$ is a linear transformation from $L_{M_{i}}^{t_{i}}(\lambda)$ into $L_{Q_{i}}^{r_{i}}(\eta), i=1,2$, with bounds $K_{1}$ and $K_{2}$ respectively, then $T$ takes $L_{M_{s}}^{t}$ into $L_{Q_{s}}^{r}$ and

$$
\|T f\|_{Q_{s}, r} \leqq K_{1}^{1-s} K_{2}^{s}\|f\|_{M_{s}, t} .
$$

This result is quite useful in establishing inequalities as the following theorem demonstrates.

THEOREM 3.2. Let $M$ be an Orlicz function, $M_{0}(x)=x^{2}$ and $M_{s}^{-1}=\left(M^{-1}\right)^{1-s}\left(M_{0}^{-1}\right)^{s}, 0 \leqq s \leqq 1$. Then for any collection of positive numbers $c_{1}, c_{2}, \cdots, c_{n}$ such that $\sum_{i=1}^{n} c_{i}=1$, the inequality

$$
\sum_{i j,=1}^{n} c_{i} c_{j}\left\|f_{i}-f_{j}\right\|_{Y_{s}}^{2 /(2-s)} \leqq 2 \gamma^{2(1-s) /(2-s)} \sum_{i=1}^{n} c_{i}\left\|f_{i}\right\|_{M_{s}}^{2 /(2-s)}
$$


holds wherever $f_{1}, f_{2}, \cdots, f_{n} \varepsilon L_{M_{s}}$ and $\gamma=\max _{1 \leqq i \leqq n}\left(1-c_{i}\right)$.

Proof. Let $M_{i}, i=1,2$ be the constant $n$-tuple with each component $M$ and $Q_{i}, i=1,2$, the constant $n^{2}$-tuple with each component $M$. Setting $t_{1}=r_{1}=1, t_{2}=r_{2}=2, c=\left(c_{1}, c_{2}, \cdots, c_{n}\right)$ and $c^{2}=\left(c_{i} c_{j}\right)_{i, j=1}^{n}$ define $T$ from $L_{M_{i}}^{t_{i}}(c)$ into $L_{Q_{i}}^{r_{i}}\left(c^{2}\right)$ by $T\left(f_{1}, f_{2}, \cdots, f_{n}\right)=$ $\left(f_{i}-f_{j}\right)_{i, j=1}^{n}$. Now

$$
\begin{aligned}
\|T f\|_{M, 1} & =\sum_{i, j=1}^{n} c_{i} c_{j}\left\|f_{i}-f_{j}\right\|_{M} \\
& \leqq \sum_{i, j=1}^{n} c_{i} c_{j}\left(\left\|f_{i}\right\|_{M}+\left\|f_{j}\right\|_{M}\right)-2 \sum_{i=1}^{n} c_{i}^{2}\left\|f_{i}\right\|_{M} \\
& =2 \sum_{i=1}^{n}\left\|f_{i}\right\|_{M}\left(1-c_{i}\right) c_{i} \leqq 2 \gamma \sum_{i=1}^{n} c_{i}\left\|f_{i}\right\|_{M}=2 \gamma\|f\|_{M, 1} .
\end{aligned}
$$

It follows from properties of Hilbert space that $\|T f\|_{M_{0}, 2} \leqq$ $\sqrt{2}\|f\|_{M_{0}, 2 \cdot}$ According to Theorem 3.1, $T$ takes $L_{M_{s}}^{2 !(2-s)}\left(c^{2}\right)$ into $L_{M s}^{2 / 2-s)}\left(c^{2}\right)$ and

$$
\|T f\|_{M_{s}, 2 /(2-s)} \leqq(2 \gamma)^{1-s}(\sqrt{2})^{s}\|f\|_{M_{s}, 2 /(2-s)} .
$$

This says

$$
\begin{aligned}
\left\{\sum_{i, j=1}^{n} c_{i} c_{j}\left\|f_{i}-f_{j}\right\|_{M_{s}}^{2 /(2-s)}\right\}^{(2-s) / 2} \leqq & (2 \gamma)^{1-s}(\sqrt{2})^{s} \\
& \left\{\sum_{i=1}^{n} c_{i}\left\|f_{i}\right\|_{M_{s}}^{2(2-s)}\right\}^{(2-s) / 2} .
\end{aligned}
$$

Raising both sides to the $2 /(2-s)$ power, the desired inequality is obtained.

The above theorem reduces to the results found in [10] for the $L_{p}$ case.

CoRollary 3.3. Let $1<p<\infty$ and $c_{1}, c_{2}, \cdots, c_{n}$ be any collection of positive numbers such that $\sum_{i=1}^{n} c_{i}=1$. Then for any $f_{1}, f_{2}, \cdots, f_{n}$ in $L_{p}$,

and

$$
\text { ( i ) } \sum_{i, j=1}^{n} c_{\imath} c_{j}\left\|f_{\imath}-f_{j}\right\|_{p}^{p} \leqq 2 \gamma^{2-p} \sum_{i=1}^{n} c_{i}\left\|f_{i}\right\|_{p}^{p}, 1 \leqq p \leqq 2
$$

(ii) $\sum_{i, j=1}^{n} c_{i} c_{j}\left\|f_{i}-f_{j}\right\|_{p}^{p^{\prime}} \leqq 2 \gamma^{2-p^{\prime}} \sum_{i=1}^{n} c_{i}\left\|f_{i}\right\|_{p^{\prime}}^{p^{\prime}} 2<p<\infty$ where $p^{\prime}=p / p-1$.

Proof. To prove (i), choose $l$ so that $1<l<p \leqq 2$ and let $M(x)=x^{l}$. If we set $s=2 / p((p-l) /(p-2)), M_{s}(x)=x^{p}$ and let $l \rightarrow 1$, then $2 /(2-s)$ approaches $p$. Similarly one can show (ii) by choosing $l>p$ and allowing $l \rightarrow \infty$. 
4. Packing. The main object of this section is to find bounds on the number $\Lambda_{M}$ where $\Lambda_{M}$ satisfies the property that for $r \leqq \Lambda_{M}$, infinite packing is possible and for $r>\Lambda_{k}$, only a finite number of balls of radius $r$ can be packed in the unit ball of the Orlicz space $L_{M}$. It has been shown by Kottman [4] that $1 / 3 \leqq \Lambda_{M} \leqq 1 / 2$. These bounds are improved below in the spaces $L_{M}[0,1]$ but it is clear that the techniques apply to a wider class of spaces.

Definition 4.1. A family of balls $\left\{B_{r}\left(f_{j}\right)\right\}_{j \in_{I}}$ of radius $r$ and centers $\left\{f_{j}\right\}_{j \in I}$ can be packed in the unit ball $B_{1}$ of $L_{M}$ provided

(i) $B_{r}\left(f_{j}\right) \subset B_{1}$ for each $j \in I$

(ii) $\operatorname{int}\left(B_{r}\left(f_{j}\right)\right) \cap \operatorname{int}\left(B_{r}\left(f_{k}\right)\right)=\phi, j \neq k$.

If a family of balls $\left\{B_{r}\left(f_{j}\right)\right\}_{j \in I}$ can be packed in $B_{1}$ then it is clear that

$$
\begin{gathered}
\left\|f_{j}\right\| \leqq 1-r, j \in I \\
\left\|f_{j}-f_{k}\right\| \geqq 2 r, j \neq k
\end{gathered}
$$

must be satisfied. Thus to find an example to serve as lower bound one needs to find vectors $f_{1}, f_{2}, \cdots$, satisfying these inequalities.

Given an Orlicz function $M$ with complement $N$, choose a sequence of disjoint measurable sets $\left\{E_{j}\right\}_{j=1}^{\infty}$ in $[0,1]$ and define

$$
g_{k}=\frac{1}{N^{-1}\left(\frac{1}{\mu\left(E_{k}\right)}\right) \mu\left(E_{k}\right)} \chi_{E_{k}}, \quad k=1,2, \cdots \text {. }
$$

Each $g_{k}$ has the property that $\left\|g_{k}\right\|_{M}=1$ (cf [5]). To compute the norm of the difference of two of these, consider the function

$$
h \equiv N^{-1}\left(\frac{1}{2 \mu\left(E_{k}\right)}\right) \chi_{E_{k}}+N^{-1}\left(\frac{1}{2 \mu\left(E_{n}\right)}\right) \chi_{E_{n}} .
$$

Then

$$
\int_{X} N(h)=\int_{E_{k}} \frac{1}{2 \mu\left(E_{k}\right)} \chi_{E_{k}}+\int_{E_{n}} \frac{1}{2 \mu\left(E_{n}\right)} \chi_{E_{n}}=1
$$

and hence $\|h\|_{N}^{\prime} \leqq 1$. Now

$$
\begin{aligned}
\left\|g_{k}-g_{n}\right\|_{M}=\sup _{\|f\|_{N}^{\prime} \leqq 1} \int_{X}\left|g_{k}-g_{n}\right||f| d \mu \\
\quad \geqq \int_{X}\left|g_{k}-g_{h}\right||h|=\frac{N^{-1}\left(\frac{1}{2 \mu\left(E_{k}\right)}\right)}{N^{-1}\left(\frac{1}{\mu\left(E_{k}\right)}\right)}+\frac{N^{-1}\left(\frac{1}{2 \mu\left(E_{n}\right)}\right)}{N^{-2}\left(\frac{1}{\mu\left(E_{n}\right)}\right)} .
\end{aligned}
$$


By choosing a subsequence we obtain

$$
\left\|g_{k}-g_{n}\right\|_{M} \geqq 2 \liminf _{x \rightarrow \infty} \frac{N^{-1}(x)}{N^{-1}(2 x)} .
$$
and

Putting $f_{k}=(1-r) g_{k}, k=1,2, \cdots$, it follows that $\left\|f_{k}\right\|=1-r$

$$
\left\|f_{k}-f_{n}\right\| \geqq(1-r) 2 \liminf _{x \rightarrow \infty} \frac{N^{-1}(x)}{N^{-1}(2 x)}
$$

Setting

$$
\beta=\liminf _{x \rightarrow \infty} \frac{N^{-1}(x)}{N^{-1}(2 x)},
$$

the inequalities (4.1) and (4.2) will be satisfied provided $(1-r) 2 \beta \geqq 2 r$ or $r \leqq 1 /(1+1 / \beta)$. This example shows that $\Lambda_{M} \geqq 1 /(1+1 / \beta)$ and leads to the following theorem.

Theorem 4.2. $L_{M}[0,1]$ be an Orlicz space with $N$ the complement of $M$ and set $M_{s}^{-1}=\left(M^{-1}\right)^{1-s}\left(M_{0}^{-1}\right)^{s}$ where $M_{0}(x)=x^{2}, 0 \leqq s \leqq 1$. Then with

$$
\begin{gathered}
\beta=\liminf _{x \rightarrow \infty} \frac{N_{s}^{-1}(x)}{N_{s}^{-1}(2 x)}, \\
\frac{1}{1+1 / \beta} \leqq \Lambda_{M_{s}} \leqq \frac{1}{1+2^{s / 2}} .
\end{gathered}
$$

Furthermore, if $1 /\left(1+2^{s / 2}\right)<r<1$ then at most a finite number $\Gamma_{H_{s}}(r)$ of balls of radius $r$ can be packed in $B_{1}$ and that number satisfies

$$
\Gamma_{M_{s}}(r) \leqq\left[1-1 / 2\left(\frac{1-r}{r}\right)^{2 / s}\right]^{-1}
$$

Proof. It remains to show (4.4) and the right hand side of (4.3). Suppose there are $n$ disjoint balls of radius $r$ with centers $f_{1}, f_{2}, \cdots, f_{n}$ packed in $B_{1}$. Then by Theorem 3.2 ,

$$
\sum_{i . j=1}^{n} c_{i} c_{j}\left\|f_{i}-f_{j}\right\|_{M_{s}}^{2 /(2-s)} \leqq 2 \gamma \frac{2(1-s)}{2-s} \sum_{i=1}^{n} c_{i}\left\|f_{i}\right\|_{M_{s}}^{2 /(2-s)}
$$

for any collection $c_{1}, c_{2}, \cdots, c_{n}$ of positive numbers such that $\sum_{i=1}^{n} c_{i}=1$. In particular, if $c_{i}=1 / n, i=1,2, \cdots, n$ then $\gamma=$ $1-1 / n$ and (4.5) reduces to 


$$
\sum_{i, j=1}^{n} \frac{1}{n^{2}}\left\|f_{i}-f_{j}\right\|_{M_{s}}^{2 /(2-s)} \leqq 2\left(1-\frac{1}{n}\right)^{2(1-s) /(2-s)} \sum_{i=1}^{n} \frac{1}{n}\left\|f_{i}\right\|_{M_{s}}^{2 /(2-s)}
$$

since the balls are disjoint, $\left\|f_{i}-f_{j}\right\| \geqq 2 r, i \neq j$, and $\left\|f_{i}\right\| \leqq 1-r$. Hence (4.6) implies

$$
\frac{1}{n^{2}} n(n-1)(2 r)^{2 /(2-s)} \leqq 2\left(\frac{n-1}{n}\right)^{2(1-s) /(2-s)} \frac{1}{n} \cdot n(1-r)^{2 /(2-s)} .
$$

This inequality then reduces to

$$
r \leqq \frac{1}{1+2^{s / 2}\left(\frac{n-1}{n}\right)^{s / 2}} .
$$

If we allow $n \rightarrow \infty$, the right hand side of (4.3) is obtained. The inequality (4.4) follows by solving (4.7) for $n$.

In the case when $M$ and $N$ have continuous derivatives, proposition 2.1 gives a lower bound in terms of $M_{s}$.

CoRollary 4.3. Let $M$ and $N$ be complementary Orlicz functions with $M$ satisfying the $\Delta_{2}$-condition. If $M$ and $N$ have continuous derivatives and $M_{s}^{-1}=\left(M^{-1}\right)^{1-s}\left(M_{0}^{-1}\right)^{s}, 0 \leqq s \leqq 1$, then

$$
\frac{1}{1+2^{(\alpha-1) / \alpha}} \leqq \Lambda_{M_{s}} \leqq \frac{1}{1+2^{s / 2}}
$$

where

$$
\alpha=\limsup _{x \rightarrow \infty} \frac{x M_{s}^{\prime}(x)}{M_{s}(x)}
$$

If we set $M(x)=x^{p}$ and use a proof similar to Corollary 3.3, the exact value $\Lambda_{M} \equiv \Lambda_{p}$ is obtained for $L^{p}, 1 \leqq p \leqq 2$.

CoRollary 4.4. Let $1 \leqq p \leqq 2$. Then $\Lambda_{p}=1 /\left(1+2^{1-1 / p}\right)$ for the space $L_{p}(\mu)$.

This holds for any measure space because, for $M(x)=x^{p}$ in the example preceding Theorem 4.2, $N^{-1}(2 x) / N^{-1}(x)=2^{1-1 / p}$ for all $x$.

The upper bounds are independent of the measure space but not the lower. Corollary 4.3 does not give the exact number for $2<p<\infty$ but gives a lower bound which was shown in [1] to be exact for $l_{p}$. However, it is demonstrated in [10] that the number in $L_{p}[0,1], 2<p<\infty$ is $1 /\left(1+2^{1 / p}\right)$. A simple generalization of this gives us new lower bounds in Orlicz spaces. 
For each positive integer $n$ and each integer $j, 0<j \leqq 2^{n}$, define $E_{n j}=\left((j-1) / 2^{n}, j / 2^{n}\right)$. Now for each integer $n$, define the function $g_{n}$ by

$$
g_{n}=\frac{1}{N^{-1}(1)} \sum_{k=1}^{2^{n}}(-1)^{k+1} \chi_{E_{n k}}
$$

where $N$ is the complementary function of the Orlicz function $M$ and $\chi_{E_{n k}}$ is the characteristic function of the set $E_{n k}$. Then $\left\|g_{n}\right\|_{M}=1$ for each $n$ and $\left\|g_{n}-g_{m}\right\|=N^{-1}(2) / N^{-1}(1), n \neq m$. Consider the spheres $S_{r}\left(f_{j}\right), j=1,2, \cdots$ with centers $f_{j}=(1-r) g_{j}$. Thus $\left\|f_{i}\right\|=1-r$ and $\left\|f_{j}-f_{k}\right\|=(1-r) N^{-1}(2) / N^{-1}(1)$. The inequalities (4.1) and (4.2) will be satisfied provided $(1-r) N^{-1}(2) / N^{-1}(1) \geqq 2 r$ or $r \leqq 1 /\left(1+2 N^{-1}(1) / N^{-1} / N^{-1}(2)\right)$.

THEOREM 4.4. Let $L_{M}[0,1]$ be an Orlicz space and set $M_{s}^{-1}=$ $\left(M^{-1}\right)^{1-s}\left(M_{s}^{-1}\right)^{s}$ where $\phi_{0}(x)=x^{2}$ and $0 \leqq s \leqq 1$. If $N_{s}$ is the complementary function to $M_{s}$, then

$$
\frac{1}{1+\frac{2 N_{s}^{-1}(1)}{N_{s}^{-1}(2)}} \leqq \Lambda_{M I_{s}} \leqq \frac{1}{1+2^{s / 2}} .
$$

The example constructed above does not depend on $[0,1]$ but rather on being able to find sets $E_{n j}$ with the same properties. However, for the $L_{p}$ spaces the construction on $[0,1]$ is enough and theorem 16.2 in [10] generalizes to the following.

COROLlaRY 4.5. Let $2 \leqq p<\infty$ and $\mu$ be any measure which is not purely atomic. Then for $L_{p}(\mu)$,

$$
\Lambda_{p}(\mu)=\frac{1}{1+2^{1 / p}} .
$$

Proof. For the space $L_{p}[0,1]$, the usual argument gives the result. It is known ([3] or [9]) that if $\mu$ is not purely atomic, $L_{p}(\mu)$ has a subspace isometric to $L_{p}[0,1]$. Suppose there are infinitely many balls of radius $r$ in $L_{p}[0,1]$ then there is a sequence of points satisfying inequalities (4.1) and (4.2) in the subspace and hence in $L_{p}(\mu)$. Thus the lower bound for $\Lambda$ in $L_{p}(\mu)$ is greater than or equal to $A_{p}$ and since the upper bound is independent of the measure, the result follows.

The problem of embedding $L_{p}[0,1]$ into $L_{r}[0,1]$ has been studied extensively and it has been shown [cf 3] that for $1 \leqq r \leqq p<2$, $L_{p}[0,1]$ is isometric to a subspace of $L_{r}[0,1]$. More recently Nielsen [6] has given conditions under which $L_{M}(0, \infty)$ is isomorphic to a 
subspace $L_{p}[0,1]$. Also the Khintchin inequality implies $l_{2}$ is isomorphic to a subspace of $L_{M}[0,1]$ for every Orlicz function $M$ and furthermore $l_{2}$ is actually isometric to a subspace of $L_{p}[0,1]$ for every $p, 1 \leqq p<\infty$. Consistent with these results is the following.

THEOREM 4.6. Let $M_{1}$ and $M_{2}$ be Orlicz functions and suppose $L_{M_{2}}$ is isometric to a subspace of $L_{M_{1}}$. Then $\Lambda_{M_{2}} \geqq \Lambda_{M_{1}}$. In particular if $l_{2}$ is isometric to a subspace of $L_{M}$ then $1 /(1+\sqrt{2)} \leqq$ $\Lambda_{M} \leqq 1 / 2$.

A converse to this theorem would be of interest. A reasonable conjecture might be to try to show that if $\left[\alpha_{M_{1}}, \alpha_{M_{2}}\right]<\left[\alpha_{M_{1}}, \alpha_{M_{2}}\right]<2$ (see [3] for definitions) and $\Lambda_{M_{2}} \geqq \Lambda_{M_{1}}$ then $L_{M_{1}}[0,1]$ is isometric to a subspace of $L_{M_{2}}[0,1]$.

For the sequence case, the situation is different. Using the example preceding Theorem 4.2 with each $E_{k}$ a singleton, it follows that $\lambda_{M} \geqq 1 /\left(1+\left(N^{-1}(1) / N^{-1}(1 / 2)\right)\right.$. The proof in [1] for $l_{p}$ depends on the strong property

$$
M^{-1}\left(\sum_{j=1}^{\infty} M\left(x_{j}\right)\right)=\|X\|_{M}
$$

where $M(x)=x^{p} / p$. If we mimic their proof the following is obtained.

THEOREM 4.7. Let $M$ and $N$ be complementary functions both satisfying the $\Lambda_{2}$-condition at 0 , and $M$ satisfies (4.9). Then for the space $l_{M}$,

$$
\frac{1}{1+\frac{N^{-1}(1)}{N^{-1}\left(\frac{1}{2}\right)}} \leqq \lambda_{M} \leqq \frac{1}{1+\frac{2}{M^{-1}(2 M(1))}}
$$

Furthermore, if $N^{-1}(1 / 2) \leqq 1 / 2 N^{-1}(1) M^{-1}(2 M(1))$, then for

$$
\frac{1}{1+\frac{2}{M^{-1}(2 M(1))}}<r \leqq \frac{1}{1+2 \frac{N^{-1}(1)}{N^{-1}(2)}},
$$

any finite number of spheres of radius $r$ can be packed in the unit ball of $l_{M}$ but not an infinite number.

Proof. The $\Delta_{2}$-condition on both $M$ and $N$ is equivalent to reflexivity. Now suppose there are an infinite number of balls of radius $r$ in $l_{M}$ with centers $y_{1}, y_{2}, \cdots$ satisfying inequalities (4.1) 
and (4.2). Assume $y$ is the weak limit point of $\left\{y_{j}\right\}$, then $y \in l_{M}$ and $\|y\| \leqq 1-r$. Let $\varepsilon>0$ and fix a positive integer $n$. Then there exists $N$ such that $\left\|\widetilde{y}_{k}\right\|<\varepsilon(1-r)$ where

$$
\widetilde{y}_{k_{j}}=\left\{\begin{array}{ll}
0 & j \leqq N \\
y_{k j} & j>N
\end{array}\right\} \text {. }
$$

Then

$$
\begin{gathered}
M\left(\frac{2 r}{1-r}\right) \leqq M\left(\frac{\left\|y_{n}-y_{m}\right\|}{1-r}\right)=\sum_{j=1}^{\infty} M\left(\frac{\left|y_{n j}-y_{m j}\right|}{1-r}\right) \\
=\sum_{j=1}^{N} M\left(\frac{\left|y_{n j}-y_{m j}\right|}{1-r}\right)+\sum_{j>N} M\left(\frac{\left|y_{n j}-y_{m j}\right|}{1-r}\right) .
\end{gathered}
$$

Now

$$
\begin{aligned}
& M^{-1}\left(\sum_{j>N} M\left(\frac{\left|y_{n j}-y_{m j}\right|}{1-r}\right)\right)=\left\|\frac{y_{n}-\widetilde{y}_{m}}{1-r}\right\| \\
& \quad \leqq \frac{\left\|y_{m}\right\|}{1-r}+\frac{\left\|\widetilde{y}_{n}\right\|}{1-r} \leqq 1+\varepsilon
\end{aligned}
$$

Thus

$$
M\left(\frac{2 r}{1-r}\right) \leqq \sum_{j=1}^{N} M\left(\frac{\left|y_{n j}-y_{m j}\right|}{1-r}\right)+M(1+\varepsilon)
$$

This argument is independent of $m$ and hence

$$
M\left(\frac{2 r}{1-r}\right)-M(1+\varepsilon) \leqq \sum_{j=1}^{N} M\left(\frac{\left|y_{n j}-y_{j}\right|}{1-r}\right) .
$$

Letting $N \rightarrow \infty$ and $\varepsilon \rightarrow 0$, this becomes

$$
M\left(\frac{2 r}{1-r}\right)-M(1) \leqq \sum_{j=1}^{\infty} M\left(\frac{\left|y_{n j}-y_{j}\right|}{1-r}\right) \text {. }
$$

Repeat the argument using $y$ in place of $y_{n}$ obtaining

$$
M\left(\frac{2 r}{1-r}\right)-M(1) \leqq \sum_{j=1}^{N^{\prime}} M\left(\frac{\left|y_{n j}-y_{j}\right|}{1-r}\right)+M(1+\varepsilon) .
$$

Now, letting $n \rightarrow \infty$ and $\varepsilon \rightarrow 0$, it follows that

$$
M\left(\frac{2 r}{1-r}\right) \leqq 2 M(1)
$$




$$
r \leqq \frac{1}{1+\frac{2}{M^{-1}(2 M(1))}}
$$

The last statement follows by constructing the example preceding Theorem 4.4 on the set $\left(1,2, \cdots, 2^{n}\right)$ in place of $[0,1]$.

CoROLlaRY 4.8. For $1 \leqq p \leqq \infty, \lambda_{p}=1 /\left(1+2^{1-1 / p}\right)$ for the spaces $l_{p}$. Furthermore if $2 \leqq p<\infty$ then for

$$
\frac{1}{1+2^{1-1 / p}}<r \leqq \frac{1}{1+2^{1 / p}}
$$

any finite number of spheres of radius $r$ can be packed in $l_{p}$ but not an infinite number.

\section{REFERENCES}

1. J. A. C. Burlack, R. A. Rankin, A. P. Robertson, The packing of spheres in the space $l_{p}$, Proc. M. A. Glasgow, 4 (1958), 145-146.

2. C. E. Cleaver, On the Extension of Lipschitz-Holder maps on Orlicz Spaces, Studia Mathematica, 27 (1972), 195-204.

3. J. Lindenstraus, and L. Tzafriri, Classical Banach Spaces, Lecture Notes in Mathematics 338, Springer-Verlag 1973.

4. C. A. Kottman, Packing and reflexivity in Banach spaces, TAMS, 150 (1970), 565-576.

5. M. A. Kransnosel'skii, and Ya. B., Rutickii, Convex Functions and Orlicz Spaces, (Translation), 1961.

6. N. J. Nielsen, On the Orlicz Function Spaces $L_{M}(0, \infty)$, Preprint Series, ISBN 82-553-0166-6, No. 4, (1974), University of Oslo.

7. R. A. Rankin, On packings of spheres in Hilbert space, Proc. M. A. Glasgow, 2 (1955), 139-144.

8. M. M. Rao, Interpolation, ergodicity, and Martingales, J. of Math. and Mech., 16 (1966), 543-568.

9. H. P. Rosenthal, On the subspaces of $L_{p}(p>2)$ spanned by sequences of independent random variables, Israel J. Math., 8 (1970), 273-303.

10. J. H. Wells and Lynn R. Williams. Imbedding and Extension Problems in Analysis, Springer-Verlag, 1975.

11. A. C. Zaanen, Linear Analysis, Amsterdam, 1953.

Received November 19, 1974 and in revised form April 12, 1976. The results in this paper were obtained while the author was a visiting professor at Georgia Institute of Technology.

Kent State UNIVERSity 



\section{PACIFIC JOURNAL OF MATHEMATICS}

\section{EDITORS}

RICHARD ARENS (Managing Editor)

University of California

Los Angeles, California 90024

\section{R. A. Beaumont}

University of Washington

Seattle, Washington 98105
J. DugundjI

Department of Mathematics

University of Southern California

Los Angeles, California 90007

D. Gilbarg and J. Milgram

Stanford University

Stanford, California 94305

\section{ASSOCIATE EDITORS}
E. F. BECKENBACH
B. H. NeumanN
F. WOLF
K. YosHIDA

\section{SUPPORTING INSTITUTIONS}

\author{
UNIVERSITY OF BRITISH COLUMBIA \\ CALIFORNIA INSTITUTE OF TECHNOLOGY \\ UNIVERSITY OF CALIFORNIA \\ MONTANA STATE UNIVERSITY \\ UNIVERSITY OF NEVADA \\ NEW MEXICO STATE UNIVERSITY \\ OREGON STATE UNIVERSITY \\ UNIVERSITY OF OREGON \\ OSAKA UNIVERSITY
}

\author{
UNIVERSITY OF SOUTHERN CALIFORNIA \\ STANFORD UNIVERSITY \\ UNIVERSITY OF HAWAII \\ UNIVERSITY OF TOKYO \\ UNIVERSITY OF UTAH \\ WASHINGTON STATE UNIVERSITY \\ UNIVERSITY OF WASHINGTON \\ AMERICAN MATHEMATICAL SOCIETY
}

The Supporting Institutions listed above contribute to the cost of publication of this Journal, but they are not owners or publishers and have no responsibility for its content or policies.

Mathematical papers intended for publication in the Pacific Journal of Mathematics should be in typed form or offset-reproduced, (not dittoed), double spaced with large margins. Please do not use built up fractions in the text of your manuscript. You may however, use them in the displayed equations. Underline Greek letters in red, German in green, and script in blue. The first paragraph or two must be capable of being used separately as a synopsis of the entire paper. Items of the bibliography should not be cited there unless absolutely necessary, in which case they must be identified by author and Journal, rather than by item number. Manuscripts, in triplicate, may be sent to any one of the editors. Please classify according to the scheme of Math. Reviews, Index to Vol. 39. All other communications should be addressed to the managing editor, or Elaine Barth, University of California, Los Angeles, California, 90024.

The Pacific Journal of Mathematics expects the author's institution to pay page charges, and reserves the right to delay publication for nonpayment of charges in case of financial emergency.

100 reprints are provided free for each article, only if page charges have been substantially paid. Additional copies may be obtained at cost in multiples of 50 .

The Pacific Journal of Mathematics is issued monthly as of January 1966. Regular subscription rate: $\$ 72.00$ a year (6 Vols., 12 issues). Special rate: $\$ 36.00$ a year to individual members of supporting institutions.

Subscriptions, orders for back numbers, and changes of address should be sent to Pacific Journal of Mathematics, 103 Highland Boulevard, Berkeley, California, 94708.

PUBLISHED BY PACIFIC JOURNAL OF MATHEMATICS, A NON-PROFIT CORPORATION

Printed at Kokusai Bunken Insatsusha (International Academic Printing Co., Ltd.), 8-8, 3-chome, Takadanobaba, Shinjuku-ku, Tokyo 160, Japan. 


\section{Pacific Journal of Mathematics \\ Vol. 65, No. $2 \quad$ October, 1976}

Andrew Adler, Weak homomorphisms and invariants: an example .......... 293

Howard Anton and William J. Pervin, Separation axioms and metric-like

functions ............................................. 299

Ron C. Blei, Sidon partitions and p-Sidon sets .................... 307

T. J. Cheatham and J. R. Smith, Regular and semisimple modules ........... 315

Charles Edward Cleaver, Packing spheres in Orlicz spaces .............. 325

Le Baron O. Ferguson and Michael D. Rusk, Korovkin sets for an operator on a

space of continuous functions ............................. 337

Rudolf Fritsch, An approximation theorem for maps into Kan fibrations ....... 347

David Sexton Gilliam, Geometry and the Radon-Nikodym theorem in strict

Mackey convergence spaces .................................

William Hery, Maximal ideals in algebras of topological algebra valued

functions ...................................... 365

Alan Hopenwasser, The radical of a reflexive operator algebra ........... 375

Bruno Kramm, A characterization of Riemann algebras................. 393

Peter K. F. Kuhfittig, Fixed points of locally contractive and nonexpansive

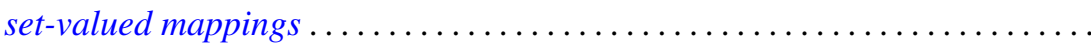

Stephen Allan McGrath, On almost everywhere convergence of Abel means of

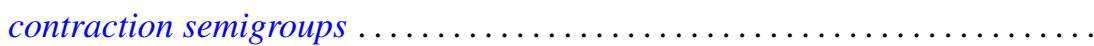

Edward Peter Merkes and Marion Wetzel, A geometric characterization of

indeterminate moment sequences............................ 409

John C. Morgan, II, The absolute Baire property ................... 421

Eli Aaron Passow and John A. Roulier, Negative theorems on generalized convex approximation .................................... 437

Louis Jackson Ratliff, Jr., A theorem on prime divisors of zero and characterizations of unmixed local domains ..............

Ellen Elizabeth Reed, A class of $T_{1}$-compactifications................... 471

Maxwell Alexander Rosenlicht, On Liouville's theory of elementary

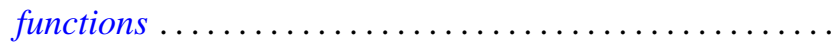

Arthur Argyle Sagle, Power-associative algebras and Riemannian

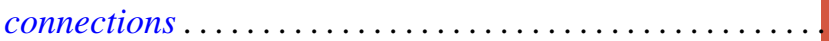

Chester Cornelius Seabury, On extending regular holomorphic maps from Stein manifolds...

Elias Sai Wan Shiu, Commutators and numerical ranges of powers of operators ...................................

Donald Mark Topkis, The structure of sublattices of the product of $n$ lattices ... 525

John Bason Wagoner, Delooping the continuous $K$-theory of a valuation

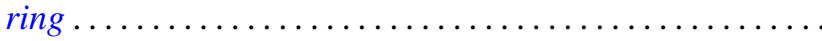

Ronson Joseph Warne, Standard regular semigroups...........

Anthony William Wickstead, The centraliser of $E \otimes_{\lambda} F \ldots$. 